\section{Resumos da XVII JOCAPE -Jornada Odontológica do Centro de Atendimento a Pacientes Especiais da Faculdade de Odontologia da Universidade de São Paulo - USP}

\section{1 de dezembro de 2017}

Presidente Docente: Profa. Dra. Marina Helena Cury Gallottini

Presidente Docente da Comissão Científica: Profa. Dra. Karem Lopez Ortega e Profa. Dra. Karin Sá Fernandes

TÍTULO: CARACTERÍSTICAS ORAIS, CRANIOFACIAIS E SISTÊMICAS DE INDIVÍDUOS COM SÍNDROME DE KABUKI: RELATO DE OITO CASOS CLÍNICOS.

NOME DOS AUTORES: NATÁLIA SILVA ANDRADE*, KAREM ORTEGA, MARINA GALLOTTINI.

\section{RESUMO}

A síndrome de Kabuki (SK) é uma desordem genética rara, descrita pela primeira vez em 1981, no Japão. A etiologia dessa síndrome está relacionada a mutações nos genes KMT2D e KDM6A, com prevalência variando entre 1:32,000 a 1:86,000 indivíduos, sem predileção por sexo ou etnia. O diagnóstico clínico da SK baseia-se em cinco características fundamentais: face dismórfica, anomalias esqueléticas, alterações dermatoglíficas, desabilidade intelectual leve a moderada e deficiência de crescimento pós-natal, além de várias outras anomalias congênitas. Manifestações bucais são comuns em indivíduos com SK e podem incluir fissura labial e/ ou palatina, língua e úvula bífidas, má oclusão e distúrbios de desenvolvimento dentários como fusão, geminação, microdontia, agenesias e hipoplasia de esmalte. Na presente série de casos, foram avaliadas características orais, craniofaciais e sistêmicas de oito pacientes com SK entre 3 e 16 anos de idade de ambos os sexos. As alterações sistêmicas encontradas incluíram infecções recorrentes (06), como pneumonia e otite média; malformações cardiovasculares (04); anomalias renais (02); epilepsia (02); e deficiência visual (02).
Os pacientes exibiam cárie dentária (05), agenesias (05), atraso na erupção dentária (04), fissura lábiopalatina (02), hipoplasia de esmalte (02), língua bífida (01), fusão dentária (01), microdontia (01) e candidíase oral (01). Os pacientes com SK apresentaram diversas comorbidades, bem como muitas alterações bucais e craniofaciais, o que faz do cirurgião-dentista um profissional de saúde fundamental para integrar a equipe multidisciplinar que assiste pessoas com SK.

TÍTULO: ALTERAÇÕES ORAIS E MAXILOFACIAIS NA SÍNDROME DE FREEMAN-SHELDON: RELATO DE CASO.

NOME DOS AUTORES: ÁQUILA ALMENARA CURTY*, VANESSA DE ASSIS SIMÕES SILVA, THAYS TEIXEIRA DE SOUZA, BRUNA LAVINAS SAYED PICCIANI, GERALDO OLIVEIRA SILVA JÚNIOR.

\section{RESUMO}

A Síndrome de Freeman Sheldon é uma desordem autossômica dominante rara, que afeta face, tórax e membros. É caracterizada por microstomia, com os lábios em forma de "passarinho", acompanhada de malformação das mãos e dos dedos com desvio ulnar e pés tortos. Este trabalho tem como objetivo descrever um caso clínico com ênfase nas alterações orais e maxilofaciais, demonstrando a importância do conhecimento desta desordem genética na Odontologia. NMPV, leucoderma, gênero feminino, 8 anos de idade, portadora da síndrome de Freeman-Sheldon, acompanhada de sua genitora que referiu queixa de dor dentária. Ao exame físico extraoral foram evidenciados olhos introjetados com telecanto primário, bochechas permanentemente insufladas com projeção dos lábios, microstomia grave, face inexpressiva, camptodactilia, pés tortos e escoliose. Ao exame físico intraoral foram observadas microglossia, palato ogival e maxila estreita, dentição mista, apinhamento dental, assim como doença cárie disseminada. Este relato mostra a importância efetiva do cirurgião-dentista no conhecimento das alterações orais e maxilofaciais para realização de procedimentos específicos instituídos com o 
objetivo de proporcionar uma melhor condição de saúde oral ao portador da síndrome.

TÍTULO: ALÍVIO DE SINTOMAS BUCAIS EM PACIENTE COM DOENÇA PULMONAR EM UMA ENFERMARIA DE CUIDADOS PALIATIVOS. RELATO DE CASO.

AUTORES: MARIANA SARMET SMIDERLE MENDES*, SUMATRA MELO DA COSTA PEREIRA JALES, RICARDO TAVARES DE CARVALHO, SERGIO SEIKI ANAGUSKO, ANA CAROLINA PORRIO DE ANDRADE.

\section{RESUMO}

A Fibrose Pulmonar Idiopática (FPI) é uma doença crônica do interstício pulmonar que se manifesta por fibrose progressiva com alta prevalência de insuficiência respiratória. Como toda doença crônica, apresenta repercussões bucais decorrentes da doença de base e/ou do seu tratamento. Neste perfil de pacientes, o Cuidado Paliativo torna-se uma necessidade. Homem de 77 anos admitido na enfermaria de Cuidados Paliativos de um hospital terciário por FPI avançada, para controle de sintomas e cuidados de fim de vida. Durante a oroscopia realizada pela equipe, recebeu diagnóstico de candidíase oral, onde foi solicitada avaliação da equipe de odontologia. Na avaliação odontológica, queixouse de língua ressecada e perda do paladar. Ao exame extraoral, paciente acamado, dispneico em repouso, em uso contínuo de máscara de venturi e lábios ressecados. Ao exame intraoral, observou-se dentição parcial com presença de placas brancas ressecadas (resíduos alimentares) em palato duro e mole, mucosa jugal e gengival, língua ressecada com saburra e hipossalivação. Foi realizada a higiene bucal com swab embebido em solução de clorexidina à $0,12 \%$, prescrição de substituto salivar e hidratante labial. O procedimento foi longo e intermitente devido à dificuldade do paciente se manter sem o suporte de oxigênio. Após o procedimento, o paciente relatou melhora de $90 \%$ dos sintomas orais. O caso evidenciou a importância da avaliação sistemática e especializada realizada pelo cirurgião-dentista inserido em uma equipe multiprofissional em
Cuidados Paliativos, que, além do diagnóstico diferencial, proporcionou alívio dos sintomas e conforto ao paciente em sua fase final de vida.

TÍTULO: ALTERAÇÕES BUCAIS EM PACIENTE COM CISTINOSE NEFROPÁTICA: RELATO DE DOIS CASOS CLÍNICOS.

AUTORES: MARINA TUMA*, JUAN FERNANDO ORDÓÑEZ-AGUILERA, ROSANA SAINT CLAIR CORREIA AIRES ANTUNES, MARINA GALLOTTINI.

\section{RESUMO}

A cistinose nefropática (CN) é um doença genética rara, autossômica recessiva, decorrente de mutações ou deleções no gene CTNS localizado no cromossomo 17p13.2. Caracteriza-se pela deposição de cistina nas células e nos tecidos, acometendo diversos órgãos, e levando por exemplo à fotofobia, retardo do crescimento, raquitismo resistente à vitamina $D$ e insuficiência renal ainda na infância. As principais alterações bucais já descritas em pessoas com $\mathrm{CN}$ são defeitos no esmalte, taurodontismo, retardo na erupção dentária e dificuldade de deglutição. Relatamos dois pacientes com $\mathrm{CN}$, enfatizando os achados bucais e a reabilitação estética e funcional de um deles. O primeiro caso é de um paciente do sexo masculino, 16 anos de idade, diagnosticado com $\mathrm{CN}$ com um ano de idade. O paciente exibia hipoplasia de esmalte afetando as superfícies vestibulares de todos os dentes, hiperplasia gengival medicamentosa grau 1 e lesão de cárie no dente 47. 0 exame radiográfico revelou presença de dente supranumerário na região do 28 . O segundo caso descreve paciente do sexo masculino, 14 anos de idade, diagnosticado com $\mathrm{CN}$ aos 3 anos de idade. $\mathrm{O}$ exame clínico revelou hipoplasia e hipocalcificação de esmalte generalizada e hiperplasia gengival medicamentosa grau 1. O exame radiográfico revelou taurodontia nos segundos molares inferiores permanentes além da presença de dente supranumerário mesio-dente. $\mathrm{O}$ tratamento incluiu gengivoplastia e confecção de facetas diretas de resina composta. $\mathrm{O}$ impacto negativo da hipoplasia de esmalte generalizada na autoestima 
dos pacientes ressalta a importância do tratamento reabilitador odontológico aqui proposto. As restaurações diretas com resina composta restabeleceram a harmonia, função e estética, além de serem de rápida execução e baixo custo.

TÍTULO: PENFIGOIDE BENIGNO DE MUCOSA EM PACIENTE COM A SÍNDROME DE GUILLAIN-BARRÉ. NOME DOS AUTORES: RODRIGO FINGER DE CARVALHO PINHO*, STEPHANIE KENIG VIVEIROS, LETÍCIA DRUMOND DE ABREU GUIMARÃES, RICARDO PELLETTI OCAÑA, DÉCIO DOS SANTOS PINTO JUNIOR

\section{RESUMO}

As doenças autoimunes são cada vez mais frequentes tendo o número de novos casos, por exemplo, triplicado nos últimos três anos nos Estados Unidos. Normalmente a Síndrome de Guillain Barré afeta mais pacientes do gênero masculino, porém, apresenta-se uma paciente do gênero feminino, 60 anos de idade, leucoderma, portadora da Síndrome de Guillain-Barré se queixava de lesões na cavidade oral recorrentes há 2 anos com intervalos de melhoras. Ao exame clínico foram notadas lesões de aspecto ulcerado, de sintomatologia dolorosa, acometendo língua, mucosa jugal e palato. Frente a estes achados clínicos optou-se por uma biópsia incisional. Ao exame histológico foi observado um fragmento de mucosa parcialmente revestida por epitélio pavimentoso estratificado paraqueratinizado onde foi possível observar uma fenda subepitelial. A lamina própria era constituída de tecido conjuntivo denso e com moderado infiltrado inflamatório. $\mathrm{Na}$ literatura não foi encontrada nenhuma relação entre a Síndrome de Guillian-Barré e as lesões em cavidade oral, mesmo sabendo-se que pacientes que apresentam uma doença autoimune são mais propensos em desenvolver uma segunda. $O$ diagnóstico de penfigóide benigno de mucosa é compatível com os aspectos clínicos e histológicos, além do diagnóstico pregresso apresentado pela paciente, mesmo não tendo sido encontrado nenhuma relação na literatura entre eles.
TÍTULO: MÚLTIPLOS CARCINOMAS ORAIS EM PACIENTE COM ANEMIA DE FANCONI TRANSPLATADO DE CÉLULASTRONCO HEMATOPOIÉTICAS.

NOME DOS AUTORES: VITOR H K MEDEIROS*, ESDRAS FAÇANHA DE CARVALHO, MARIA PAULA SIQUEIRA DE MELO PERES, NAYARA HANO, JULIANA BERTOLDI FRANCO.

\section{RESUMO}

Anemia de Fanconi (AF) é uma doença genética, autossômica recessiva, ligada ao cromossomo $\mathrm{X}$, que ocasiona a falência da medula óssea. Os pacientes afetados podem apresentar anomalias somáticas e neoplasias como as leucemias mielóide aguda e tumores de cabeça e pescoço. Pacientes com AF tratados com transplante de células-tronco hematopoiéticas (TCTH) apresentam um aumento significativo do risco de desenvolvimento de tumores. O relato de caso é do paciente do sexo masculino, diagnosticado com AF, com realização de TCTH aos 4 anos de idade. Com 14 anos de idade, paciente compareceu para consulta com lesão ulcerada, de bordas irregulares, endurecida a palpação, indolor, medindo $3 \mathrm{~cm}$, em borda direita de língua, com evolução de 20 dias, associada a linfonodomegalia submandibular. Foi realizada biópsia incisional da lesão e a análise anatomopatológica revelou um carcinoma espinocelular (CEC). Paciente foi submetido a cirurgia para ressecção da lesão e radioterapia de cabeça e pescoço, com seguimento odontológico após o tratamento e orientações de autoexame da boca. Em 2017, o paciente procurou atendimento devido a lesão em língua esquerda observada durante autoexame da cavidade oral. Observou-se outra lesão ulcerada em borda lateral esquerda de língua, de bordas elevadas e endurecida ao toque. Foi realizada biópsia incisional, com laudo de um novo CEC. O paciente foi submetido a cirurgia e reconstrução microcirúrgica da área. Devido a susceptibilidade do desenvolvimento de tumores a equipe interdisciplinar que assiste o paciente deve estar ciente desse risco, cabendo ao cirurgiãodentista exames periódicos da cavidade oral para o diagnóstico precoce das lesões orais, tratamento 
incipiente e melhor prognóstico, assim como treinar o paciente para a realização do autoexame.

TÍTULO: INTERCORRÊNCIA NO TRATAMENTO DE OSTEONECROSE POR BIFOSFONATO EM PACIENTE COM SÍNDROME DO ANTICORPO ANTIFOSFOLIPÍDEO.

NOME DOS AUTORES: VITOR H K MEDEIROS*, SHADDIA KARLA CRUZ DOS SANTOS, NAYARA HANO, MARIA PAULA SIQUEIRA DE MELO PERES, JULIANA BERTOLDI FRANCO

\section{RESUMO}

A Síndrome do anticorpo antifosfolipídeo (SAF) é uma doença autoimune, caracterizada por eventos trombóticos e/ou complicações durante a gravidez, além da presença persistente de anticorpos antifosfolipídeo. O tratamento é realizado com drogas antitrombóticas (varfarina), e antiagregante plaquetário quando existe risco de doença coronariana associada. O relato de caso descreve o tratamento de uma paciente com osteonecrose dos maxilares por bifosfonato oral (alendronato de sódio) diagnosticada com SAF, osteoporose, aterosclerose, fazendo uso de varfarina, ácido acetilsalicílico, heparina de baixo peso molecular e alendronato. Clinicamente foi observada fistula intra-oral com drenagem ativa de secreção purulenta em área de exodontias há 2 meses. No raio-x panorâmico observou-se sequestro ósseo. Optou-se por debridamento cirúrgico, para remoção do sequestro e limpeza da área, com INR= 1,3 e TTPa= 37,9seg, em ambulatório, com $\mathrm{o}$ auxílio de métodos hemostáticos locais. Apresentou dois episódios de sangramento no pós-operatório, com a presença de coágulo mal formado e sangramento importante (INR=2,85 e TTPa= 51,5seg). Foi discutido com a equipe médica que optou por suspender o AAS e a heparina de baixo peso molecular, e reabordagem da área com controle do sangramento com meio hemostático local, sem sangramento e sem intercorrências no pósoperatório. Portanto, cabe ao profissional o conhecimento sobre patologias sistêmicas, anticoagulantes orais, e alterações do metabolismo óssea para a realização do tratamento odontológico seguro, assim como saber resolver as complicações. A discussão com a equipe interdisciplinar que assiste o paciente é determinante para sucesso da conduta odontológica

TÍTULO: TRATAMENTO RESTAURADOR ESTÉTICO INFANTIL EM PACIENTE COM COLESTASE NEONATAL - RELATO DE CASO.

NOME DOS AUTORES: ANA CAROLINA CORAZZA PEDRO*, RUTH MÓNICA CARRANZA SOTELO, TACIANA MARA COUTO DA SILVA, LEVY ANDERSON C ALVES, ANA LÍDIA CIAMPONI

\section{RESUMO}

A colestase neonatal é resultado da diminuição da síntese dos ácidos biliares na excreção dos componentes para o intestino delgado. As manifestações sistêmicas dessa patologia são: colúria, acolia fetal, hipercolesterolemia e hiperbilirrubinemia. A hiperbilirrubinemia pode gerar má formações no tecido mineralizado, tanto em espessura quanto na composição estrutural, provocando assim manchamento intrínseco de coloração esverdeada/ amarelada nos tecidos dentários, podendo acometer dentição decídua e permanente. Paciente do sexo feminino, 5 anos, foi atendida no CAPE/GEAPE- FOUSP para tratamento do quadro de cárie de acometimento precoce na infância. Após as restaurações dos elementos $64,75,85$ a paciente deu início ao tratamento estético dos elementos $51,52,53,61,62,63,71,72,73,81,82$ e 83 com coroas diretas de resina composta, utilizando matriz de celulóide para melhor adaptação. $\mathrm{O}$ uso de coroas diretas em resina composta com auxílio de matriz está indicado para destruições dentarias extensas, reduzindo a necessidade de uma etapa laboratorial e assim diminuindo o número de sessões. Entretanto, demanda-se do profissional conhecimento e habilidade para avaliar se há ou não a possibilidade de utilizar esse método, exigindo também do paciente certa colaboração. $O$ tratamento estético na infância também tem papel importante sob o ponto de vista funcional, pois restabelece as estruturas dentarias do paciente, possibilitando que o mesmo mastigue adequadamente, bem como permite a pronuncia 
de fonemas de forma adequada. Em relação a estética, a reabilitação protética garante ao paciente a reintrodução na sociedade e melhor qualidade de vida.

TÍTULO: PRÓTESE ESTÉTICA PROVISÓRIA EM PACIENTE COM OSTEOGÊNESE IMPERFEITA: RELATO DE CASO CLÍNICO.

AUTORES: LETÍCIA BARROSO MORGADO*, DANIEL A'OMES NOGUEIRA FERNANDES, JEANNE CARLA STEFFEN, ADRIANA DE OLIVEIRA LIRA ORTEGA, MARINA GALLOTTINI.

\section{RESUMO}

A Osteogênese Imperfeita (OI) é uma anomalia caracterizada pelo aumento da fragilidade óssea decorrente da alteração de síntese do colágeno tipo I, causando impacto eventual na formação dentária. A dentinogênese imperfeita (DI) é a alteração bucal mais importante nesses casos e é caracterizada pela presença de dentes quebradiços coloridos de cor amarelada e opalescentes e podem afetar a dentição primária e secundária. MGCF, 17 anos, do sexo feminino, diagnosticada com OI tipo IV (caracteriza-se por fragilidade óssea e as fraturas podem apresentar-se a qualquer idade e a maioria desses pacientes tem baixa estatura). Apresentou-se com DI, fratura no elemento 31 e insatisfeita com a estética. Foi feito a exodontia do 31 e o tratamento proposto, visando preservar os dentes sem prepará-los proteticamente, foi a confecção de um par de próteses provisórias sobre os dentes hígidos. Posteriormente feitas as moldagens das arcadas com alginato. No modelo de gesso, foram feitas as bases de prova de resina acrílica com os planos em cera, seguidos das montagens dos dentes de estoque e posteriormente a acrilização das próteses tipo "capa de dentes", com resultado estético satisfatório. A paciente ficou ciente de que as próteses são provisórias removíveis sobre os dentes, bem como recebeu orientações de higiene bucal. Além disso, a paciente está incluída em programa preventivo, com consultas periódicas de prevenção, para análise do Índice de Higiene Oral Simplificado (IHO-S) e do Índice Comunitário Periodontal - ICP, com o intuito de verificar se a manutenção da saúde bucal após instalação das próteses removíveis estéticas. Recursos protéticos, mesmo que provisórios, podem ser viáveis em adolescente com OI, como resposta à demanda estética dessa faixa etária.

TÍTULO: SÍNDROME DE SECKEL: O NANISMO DE CABEÇA DE PÁSSARO.

AUTORES: LUMA COLLINO*, CAROLINE TREFIGLIO ROCHA, GRAZIELA LEONTINA OLOPES, JOÃO CARLOS DA ROCHA, THIAGO FERNANDO DA SILVA RESUMO

A Síndrome de Seckel (SCKL) é uma patologia genética rara, de herança autossômica recessiva e que apresenta uma incidência inferior a 1:1.000.000 de nativivos. Essa desordem é a forma mais comum de nanismo microcefálico e não apresenta predomínio geográfico, étnico ou ligada ao sexo. Os traços mais característicos são a grave restrição do crescimento intra-uterino e do desenvolvimento pós-natal, resultando em um nanismo severo e proporcionado. Os indivíduos afetados apresentam uma microcefalia severa, microretrognatia com nariz proeminente $\mathrm{e}$ arqueado (semelhante ao bico de pássaros) e craniossinostose. Relatamos o caso do paciente A.A.S., sexo masculino, 23 anos, leucoderma, filho de pais consanguíneos. O paciente encontra-se em tratamento odontológico, a nível ambulatorial, com uso de contenção física e apoios. A história médica pregressa do paciente foi obtida com o auxílio mãe e de exames médicos laboratoriais e radiográficos levados por ela para a consulta. 0 paciente apresenta retardo do crescimento pôndero-estatural; holoprosencefalia semilobar; bifidez de $\mathrm{C} 1$ e hipoplasia do $12^{\circ}$ arco costal; micro e braquiocefalia; hipertonia muscular (tetraparético assimétrico); atetose com comprometimento do hemicorpo esquerdo; encurtamento dos joelhos; hipoplasia no terço médio da face, orelhas de implantação baixa, pregas epicânticas, fendas palpebrais oblíquas, nariz em cela, filtro longo e apagado, lábios fino, prega palmar única bilateral; clinodactilia, hipoplasia da falange média; maior distância entre primeiro e o segundo artelho; hipoplasia escrotal; 
luxação do quadril e catarata e hipermetropia. No exame clínico foi observado uma assimetria facial, microrretrognatismo, agenesia parcial, hipoplasia do esmalte, palato atrésico, cáries, problemas periodontais e bruxismo.

TÍTULO: PÚRPURA TROMBOCITOPÊNICA IDIOPÁTICA - HEMORRAGIA EXTENSA EM OROFARÍNGE: RELATO DE CASO.

AUTORES: NAYARA YURI HANO*, SAHAR GANZ RIMAN, VITOR HUGO MEDEIROS, JORGE FERREIRA ARAUJO, LUIZ ALBERTO SOARES JUNIOR.

\section{RESUMO}

A purpura trombocitopênica primária (PTI) é uma doença auto-imune caracterizada por trombocitopenia com ou sem eventos hemorrágicos. O dianóstico é alcançado após excluir outras causas de trombocitopenia, é raro sendo a incidência estimada entre 1,6 e 3,9 / 100,000 adultos / ano e a prevalência é de aproximadamente 50 / 100,000 adultos e com maior prevalência em mulheres. $O$ objetivo desde trabalho é relatar o caso de uma jovem de 25 anos, que apresentou sangramento gengival e equimoses. $\mathrm{Na}$ admissão em pronto socorro, a contagem de plaquetas no sangue foi de $4.000 / \mathrm{mm} 3$ sem alterações em mielograma e leucograma. Foi realizado tratamento com corticosteróide oral, pulsoterapia, transfusão plaquetária e imunoglobulina sem obtenção de incremento plaquetário. Ao exame intraoral apresentava mega coágulos malformados em pilar amigdaliano estendendo se em dorso e lateral de língua, e rebordo alveolar inferior esquerdo, com história pregressa de exodontia de dente 46. Em avaliação pela odontologia a pedido da equipe de hematologia, foi realizado remoção parcial de coágulos malformados, curativo com transamin e sutura em massa constatando ausência de sangramento de origem dentária e sim de orofarínge. Em exame de imagem de tomografia foi confirmado sangramento em orofaringea sendo o tratamento de escolha transfusão de Fator VIla e plaquetas obtendo com regressão total dos coágulos orais. Verificou-se que por meio do acompanhamento multiprofissional, foi possível identificar a origem real do sangramento e a intervenção correta para o caso.

TÍTULO: OSTEONECROSE POR MEDICAMENTOS EM DISPLASIA CEMENTO - ÓSSEA PERIAPICAL NO PACIENTE GERIÁTRICO: RELATO DE CASO.

AUTORES: NAYARA YURI HANO*, RAFAEL LODI, ERIKA DE PAULA, MARIA PAULA SIQUEIRA DE MELO PERES, JULIANA BERTOLDI FRANCO.

\section{RESUMO}

A displasia cemento-óssea é uma lesão óssea benigna, caracterizada pela substituição do tecido ósseo por tecido fibroso, dividida em três subtipos: periapical, focal e florida. A displasia cementoóssea periapical ocorre geralmente na região apical dos dentes anteriores da mandíbula, com vitalidade pulpar. Apresenta predileção por mulheres (14:1), e aproximadamente $70 \%$ dos casos, em negros. Estas lesões são assintomáticas e encontradas em exames de rotina e radiográfico. Paciente ALV, 91 anos, sexo feminino, negra, em acompanhamento pela geriatria devido a osteoporose, em uso de alendronato de sódio, com queixa de dor em região anterior de mandíbula após exodontia dentária há aproximadamente 10 meses. Ao exame clínico observou-se em mandíbula anterior a presença de abaulamento de cortical, exposição óssea e supuração ativa. No raio-x panorâmico notou-se uma lesão de radiopacidade mista em região anterior de mandíbula. A hipótese diagnóstica foi de osteonecrose por medicamentos de displasia cemento-óssea periapical, pelo uso do alendronato. Optou-se por antibioticoterapia prévia, e realização de desbridamento cirúrgico da área. No pós-operatório de 7 dias observou-se deiscência da ferida. Optou-se pela instituição de terapia fotodinâmica na área cirúrgica, sendo associado LASER de baixa potência (vermelho, $100 \mathrm{~W}, 6 \mathrm{~J} / \mathrm{cm}^{2}$, pontual) com azul de metileno 0,05\%. Após 7 dias, notou-se presença de tecido de granulação em toda loja cirúrgica, com completa cicatrização em 3 semanas. A associação da anamnese, principalmente em relação aos 
medicamentos em uso atual ou prévio, com exames clínicos e complementares são determinantes para o diagnóstico correto, assim como a junção de terapias e procedimentos são imperativos para o sucesso do tratamento.

TítULO: LESÃO INTRA-ORAL DE MIELOMA MÚLTIPLO COMO MARCADOR DE PROGRESSÃO DE DOENÇA.

AUTORES: CRISTIANE TEIXEIRA LEITE*, MARIA LUIZA VELOSO WATANABE, FABIANA MARTINS, PAULO HENRIQUE BRAZ-SILVA, NATHALIE PEPE MEDEIROS DE REZENDE.

\section{RESUMO}

Mieloma múltiplo (MM) é uma neoplasia maligna de origem hematopoiética, de proliferação monoclonal de plasmócitos, levando a lesões ósseas líticas, fratura patológica, insuficiência renal e anemia. Tem predileção por homens, na faixa de 65 anos. O tratamento, na doença ativa, inclui corticóide, bisfosfonatos, quimioterapia (QT) e TCTH. A sobrevida varia de 4 a 10 anos. Caso clínico: JJML, sexo masculino, 65 anos, diagnosticado com MM (2001), após fratura patológica de úmero. Exames radiográficos mostraram lesões ósseas em coluna e fêmur. Mielograma evidenciou $90 \%$ de plasmócitos e o paciente foi submetido a QT (protocolo VAD), seguido de TCTH autólogo. Após o TCTH, utilizou interferon (2002 a 2011), pamidronato (desde 2003) e corticoide (desde 2013). Em 2013, realizou radioterapia (RDT) em arcos costais e nova QT (protocolo CYBORD). Após 3 anos, cursou com piora das lesões em coluna e fêmur, realizando cirurgia e RDT local. Desde então, realiza QT com melfalana (1 semana a cada 21 dias). Em 07/2017 foi encaminhado à Odontologia do HEMC pela oncohematologia da FMABC, com "bolha" em maxila, sob a prótese total, com 2 meses de evolução, assintomático. Ao exame físico intraoral, observou-se aumento de volume em rebordo alveolar superior posterior, com $3 \mathrm{~cm}$ de extensão, flácido, com ulceração central e teleangectasia periférica. A panorâmica mostrou destruição óssea em maxila. TC evidenciou destruição do rebordo alveolar, assoalho de seio maxilar e palato duro, e invasão de mucosa jugal e fossa pterigopalatina. Biópsia incisional, enviada à Patologia Bucal/FOUSP, revelou plasmocitoma. O paciente realizará RDT local e reavaliação na FMABC. Cabe ao cirurgião dentista acompanhar pacientes com $\mathrm{MM}$, tratar complicações advindas do tratamento e identificar focos orais da doença.

TÍTULO: CARACTERÍSTICAS ORAIS E SISTÊMICAS DA SÍNDROME POLIGLANDULAR AUTOIMUNE TIPO I: RELATO DE CASO CLÍNICO.

AUTORES: NATÁLIA SILVA ANDRADE*, MARINA TUMA, FABIANA MARTINS, MARINA GALLOTTINI. RESUMO

A Síndrome Poliglandular Autoimune Tipo 1 (SPA 1) é uma desordem autossômica recessiva rara, caracterizada por acometimento autoimune a diversos órgãos e causada por mutações no gene AIRE (autoimmune regulator) que participa da manutenção da autotolerância do indivíduo. As manifestações clínicas da síndrome são extremamente variáveis. A tríade clássica é composta por candidíase mucocutânea crônica, hipoparatiroidismo e doença de Addison. As manifestações bucais mais comuns são candidíase oral, defeitos de esmalte, doença periodontal e hipossalivação. $O$ presente relato descreve paciente do sexo feminino, 42 anos de idade, feoderma, com diagnóstico de SPA 1, apresentando diabetes mellitus tipo 1 , retinopatia, cirrose hepática por hepatite crônica autoimune, gastrite, anemia, insuficiência pancreática, epilepsia, doença celíaca, calcificação cerebral, depressão e alergia a metoclopramida e dipirona. A paciente fazia uso de insulina, calcitriol, carbonato de cálcio, vitamina B12, pancreatina, venlafaxina e lamotrigina. A queixa principal odontológica foi de perda de vários dentes e necessidade de prótese. Clinicamente, foram observadas microstomia, diminuição do fluxo salivar, queilite angular, úlceras em lábio superior e inferior, presença de hipoplasia de esmalte, reabsorções radiculares, calcificações pulpares e candidíase hiperplásica confirmada por exame citológico. Foi realizada prescrição de bochechos com nistatina por 15 dias e aplicação de terapia 
fotodinâmica antibiótica. Indivíduos com SPA 1 apresentaram grande heterogeneidade de características sistêmicas, o que torna o tratamento odontológico desses pacientes desafiador. O cirurgião-dentista deve estar apto para atuar junto à equipe multidisciplinar no manejo das alterações bucais relacionadas a essa síndrome.

TÍTULO: SÍNDROME OPSOCLONUS-MIOCLONUS ASSOCIADA A NEUROBLASTOMA EM MEDIASTINO POSTERIOR - RELATO DE CASO CLÍNICO.

AUTORES: LAYSA YOSHIOKA*, LAIS LIARTE, ANAELISA FIGUEIREDO, ANA LIDIA CIAMPONI.

\section{RESUMO}

A síndrome opsoclonus-mioclonus (ORPHA 1183), também conhecida como síndrome de Kinsbourne (SK), é uma doença neuroinflamatória rara caracterizada pela presença de opsoclonia (movimentos oculares rápidos, irregulares, horizontais e verticais), mioclonias que podem afetar tronco, extremidades ou face, ataxia cerebelar e mudanças comportamentais. A incidência anual da doença é de 1:5.000.000. A etiologia da SK ainda não foi elucidada, pode-se observar a identificação de casos idiopáticos, associação com infecções virais, doenças autoimunes e, em $50 \%$ dos casos está associado a neuroblastoma. Não existem relatos clínicos que descrevam as condições odontológicas nesses pacientes. Paciente do gênero masculino, 4 anos, leucoderma, compareceu ao GEAPE-FOUSP acompanhado pelos pais. Durante anamnese, os pais relataram que $\mathrm{o}$ paciente referido foi diagnosticado aos 14 meses de vida com SK associada a neuroblastoma em mediastino posterior - CID C383 (quadro paraneoplásico). Atualmente está em acompanhamento médico com neuropediatra e oncologista. Durante exame clínico odontológico, observamos fratura de esmalte na região incisal dos dentes 51 e 61, lesões de cárie na face oclusal dos dentes 65,75 e 85 e fusão dos dentes 71 e 72 . Realizamos radiografia panorâmica, e observamos que a cronologia de formação dentária corresponde com a idade biológica. Durante as consultas, o paciente demonstrou aceitação pelo tratamento, porém em alguns dias demonstrou certa irritação e/ou inquietabilidade. Por se tratar de uma doença rara é importante que seja realizado relatos de caso e estudos que colaborem com o conhecimento da síndrome e a prática clínica.

TÍTULO: MANEJO MULTIDISCIPLINAR DE EFEITOS COLATERAIS DO TRATAMENTO ONCOLÓGICO EM INDIVÍDUO COM SARCOMA ALVEOLAR DE LÍNGUA. AUTORES: NATALIA GARCIA SANTAELLA*, DÉBORA FOGER, DANILA RODRIGUES COSTA, CÁSSIA MARIA FISCHER RUBIRA, PAULO SÉRGIO DA SILVA SANTOS.

\section{RESUMO}

O Sarcoma Alveolar de Partes Moles é raro e representa $0,5 \%$ a $1 \%$ dos sarcomas de tecidos moles. Paciente de 17 anos, leucoderma, mulher, com queixa de "Dor nos sisos e bochechas". Realizou tratamento cirúrgico, quimioterápico e radioterápico há 2 anos. Durante avaliação observou-se trismo severo, pericoronarite, presença de exsudato e mobilidade no dente 38 . A imagem radiográfica panorâmica apresentou área radiolúcida, mal definida na distal do 38 , sendo diagnosticado osteorradionecrose. As condutas foram: raspagem periodontal e irrigação com clorexidina, planejamento da exodontia, antibioticoterapia e miorrelaxante e encaminhamento a fisioterapia e fonoaudiologia. No trans-operatório da exodontia do 38 presença de odor necrótico no alvéolo. Foi realizado uso diário de clorexidina, antibioticoterapia e sessões quinzenais de irrigação com clorexidina. O diagnóstico fisioterapêutico foi trismo severo do masseter. Foi realizado termoterapia, mobilização da articulação temporomandibular, alongamento intraoral do músculo masseter e prescrito exercícios de abertura de boca. O tratamento fisioterapêutico manteve continuidade 7 dias após a extração. A avaliação fonoaudiológica revelou tônus diminuído de lábio inferior, alteração na mobilidade de lábios, língua, bochechas e mandíbula e sinais e sintomas de disfagia orofaríngea para alimentos sólidos. A conduta fonoaudiológica consistiu em exercícios para 
tonicidade de lábios e mobilidade de lábios, língua, bochechas e mandíbula e orientações quanto a manobras protetoras e facilitadoras da deglutição. A paciente encontra-se em acompanhamento fonoaudiológico, onde foi observado melhora na fala e deglutição. A atuação multidisciplinar foi fundamental no tratamento das complicações do tratamento oncológico.

TíTULO: MANIFESTAÇÃO ORAL DE DOENÇA DO ENXERTO-CONTRA-HOSPEDEIRO MIMETIZANDO PERIODONTITE ULCERATIVA NECROSANTE.

AUTORES: ALOIZIO PREMOLI MACIEL*, REYNA AGUILAR QUISPE, DENISE TOSTES OLIVEIRA, CÁSSIA MARIA FISHER RUBIRA, PAULO SÉRGIO DA SILVA SANTOS

\section{RESUMO}

O transplante de medula óssea é uma das principais modalidades de tratamento para Leucemia com altas taxas de morbimortalidade. Mulher de 36 anos, com queixa de "minha boca está ardendo". Sintomática a alimentação em boca toda. Diagnosticada com Leucemia Linfoblástica Aguda de células B há 2 anos, estava internada por recidiva da doença após rejeição de transplante de medula óssea alógeno há 2 meses. Evoluiu para sepse e reação alérgica à vancomicina após ciclo quimioterápico com HyperCVAD de resgate. Ao exame físico intraoral notou-se perdas das papilas interdentárias dos dentes 42,41,31,22,25 e 26 associada a pseudomembrana brancoacinzentada, heterogênea de bordas irregulares, fétida com tumefação violácea progredindo para gengiva marginal livre e inserida. Realizamos cultura microbiana da psudomembrana da região dos dentes 26 e 31 sob o diagnóstico presuntivo de Periodontite Ulcerativa Necrosante. Introduziu-se bochechos com clorexidina a $0,12 \%$ sem álcool, peróxido de hidrogênio a $2 \%$ e piperaciclina/tazobactam para tratamento antimicrobiano para Pseudomonas aeruginosa. Devido a persistência da lesão em região dos dentes 25 e 26, foi realizado raspagem periodontal e biópsia incisional, o qual revelou separação do epitélio pavimento estratificado da submucosa, bolha na submucosa com necrose fibrinoíde com pouco infiltrado inflamatório compatível com Necrose Epitelial Toxica (NET). Após duas semanas do diagnóstico a paciente evoluiu com doença do enxerto-conta-hospedeiro (DECH) com comprometimento hepático, cutâneo e bucal, fechando o diagnóstico de NET associada a DECH. O diagnóstico oral precoce da DECH é importante para definição da conduta de tratamento e diminuição das morbimortalidades que a envolve, neste caso com manifestação primária bucal da NET.

TÍTULO: COMUNICAÇÃO BUCO-NASAL ASSOCIADA AO USO DE BISFOSFONATOS E COMPROMETIMENTO SISTÊMICO.

AUTORES: ÁNGEL TERRERO-PÉREZ*, ANA LÚCIA ALVARES CAPELOZZA, PAULO SÉRGIO DA SILVA SANTOS, RENATO YASSUTAKA FARIA YAEDÚ, IZABEL REGINA FISCHER RUBIRA-BULLEN.

\section{RESUMO}

Idosos possuem várias comorbidades sistêmicas, como o comprometimento cardiovascular, osteoporose, dislipidemia, entre outras. Os Bisfosfonatos (BF) são utilizados no tratamento de osteoporose, entretanto a osteonecrose (ON) é uma complicação importante decorrente do uso prolongado, caracterizada por exposição óssea nos maxilares por mais de 8 semanas. Relatamos o caso de uma mulher de 84 anos, leucoderma, edêntula, com histórico de fistula nasal lado direito, evolução de 2 anos, com sintomatologia dolorosa. Apresentava insuficiência valvar aórtica de importante repercussão hemodinâmica, hipertensão arterial, dislipidemia, hipertireoidismo e osteoporose severa com fratura vertebral, uso de ácido zoledrônico endovenoso há 10 anos e há cerca de 5 anos uso de ibandronato. Clinicamente, apresentava comunicação buco-nasal (CBN) com $8 \mathrm{~mm}$ de exposição óssea na região anterior da maxila (RAM), mucosa eritematosa, sangrante ao toque e discreta drenagem purulenta. A TCFC mostrou imagem hipodensa de reabsorção óssea, sequestro ósseo de $13 \mathrm{~mm}$ e CBN na RAM. Os achados sugeriram $\mathrm{ON}$ por uso de BF e comprometimento sistêmico. Removeu-se o osso exposto e no controle pós 6 meses, contatou-se a 
recorrência de discreta fistula com secreção purulenta, bem como alteração na TCFC. Foi prescrito Dalacin-c (Dc) 300mg por 14 dias, mas apresentou dor no estomago e dificuldade para se alimentar, sendo o medicamento suspenso e orientada ao uso de enxaguatório Perioxidin $500 \mathrm{ml}$ (3x/dia). Após 1 semana, paciente retornou sem queixas, sendo observado o trajeto da fistula sem secreção, foi prescrito novamente Dc e soro fisiológico para instalação nasal, havendo melhora na sintomatologia. Concluímos que as diversas estratégias de tratamento para $\mathrm{ON}$ associada a BF e comprometimento sistêmico foram efetivas.

TÍTULO: CONDUTA ODONTOLÓGICA CIRÚRGICA E MEDICAMENTOSA EM PACIENTE COM FIBROMATOSE HIALINA JUVENIL: RELATO DE CASO.

AUTORES: RENATA RODRIGUES MERGULHÃO, ANA LÍDIA CIAMPONI, LUCIANE AZEVEDO.

\section{RESUMO}

A Fibromatose Hialina Juvenil (FHJ) é uma doença rara do tecido conectivo, autossômica recessiva, afeta o cromossomo $214 \mathrm{q}$, o qual codifica a morfogênese capilar proteína-2. A prevalência é desconhecida e aproximadamente 70 casos em literatura. V.G.S, gênero feminino, 9 anos, com diagnóstico de FHJ. Realizado exame clínico odontológico no GEAPE/CAPE, foi observado crescimento e inflamação gengival localizada, espessamento labial e radiograficamente, dentes decíduos com rizólise. Foi submetida a gengivectomias (abril /2017-outubro /2017) porém, manteve dificuldade na alimentação e na abertura bucal durante a higiene oral; devido à recidiva do crescimento gengival e espessamento labial. Clinicamente observamos nódulos subcutâneos em regiões da face, couro cabeludo, pescoço, orelhas, mãos, vários membros encurtados e contraturas articulares, que representa alteração do tecido fibroso hialinizado. O plano de tratamento odontológico incluiu, condicionamento psicológico, gengivectomias parciais com laser de Diodo (Biolase- pulsado-3W) e duas aplicações de dipropionato de betametasona em mucosa labial (abril e setembro/2017). Após conduta odontológica notamos melhora da hipertrofia gengival, aumento no limite de abertura bucal e presença de vedamento labial. É fundamental o papel do cirurgião dentista especializado, no manejo de pacientes com FHJ que vai desde o diagnóstico de alterações bucais até manejo especializado, melhorando assim a qualidade de vida destes pacientes.

TÍTULO: PÊNFIGO VULGAR ORAL: O PAPEL DO CIRURGIÃO-DENTISTA NO DIAGNÓSTICO E TRATAMENTO ODONTOLÓGICO.

AUTORES: BRUNA LAVINAS SAYED PICCIANI*, KARINA MORIEL TAVARES, THAYS TEIXEIRA DE SOUZA, BRUNA MICHALSKI DOS SANTOS, GERALDO DE OLIVEIRA SILVA.

\section{RESUMO}

O Pênfigo Vulgar é uma doença mucocutânea autoimune comum, caracterizado por formação de bolhas intraepiteliais. As lesões orais recebem destaque por constituírem, frequentemente, o primeiro sinal da doença e por serem consideradas lesões de difícil resolução. Apesar do controle medicamentoso, a saúde oral adequada é essencial para controle das lesões orais. Deste modo, o objetivo deste trabalho é relatar um caso de manifestações orais de pênfigo vulgar, enfatizando a importância do Cirurgião-Dentista no diagnóstico e tratamento das lesões orais; destacando a manutenção da saúde oral como fator sine qua non para controle destas lesões. Homem, 55 anos, com queixa de dor e lesões ulceradas em mucosas jugal, labial e gengiva há 6 meses. Após realização de biópsia incisional foi confirmado o diagnóstico de pênfigo vulgar. Para o tratamento das lesões orais foram confeccionadas moldeiras de silicone para uso do gel composto de hidrocortisona a $1 \%$ e lidocaína a 0,5\%, três vezes ao dia, durante 30 minutos. Somado a isso, prescrição de bochecho com corticoide, raspagem supragengival, polimento coronário e troca de restaurações mal adaptadas, foram realizados. 0 paciente encontrase em acompanhamento há 2 anos, mantendo a saúde oral, utilizando corticosteroide tópico quando há exacerbação das lesões. A partir deste 
relato, foram criadas orientações para o tratamento odontológico destes pacientes. Podemos concluir que as lesões orais representam os primeiros sinais clínicos desta doença, sendo de extrema importância que o Cirurgião-Dentista esteja apto para identificar e tratar as manifestações orais. Além da responsabilidade na orientação da manutenção da saúde oral, minimizando assim o sofrimento dos pacientes e a evolução para um quadro mais grave da doença.

TÍTULO: ANÁLISE LONGITUDINAL DO MICROBIOMA BUCAL DE PACIENTES PEDIÁTRICOS COM ANEMIA FALCIFORME SOB TRATAMENTO COM HIDROXIURÉIA.

NOME DOS AUTORES: MARCIA HIROMI TANAKA*, LAURA SOARES SOUTO LEPESQUEUR, GABRIELA DE MORAIS GOUVÊA LIMA, CRISTIANE YUMI KOGAITO, BRUCE JAY PASTER.

\section{RESUMO}

Introdução: $\mathrm{O}$ tratamento com hidroxiuréia (HU) nos pacientes com anemia falciforme (AF) traz efeitos clínicos positivos porém não foram detectados estudos sobre os efeitos bucais deste tratamento. Objetivo: Analisar os efeitos da HU no microbioma bucal de pacientes com AF. Métodos: Vinte e cinco crianças com AF, com idades de 3 a 15 anos, foram avaliadas no início do tratamento com HU e longitudinalmente após 3 e 6 meses de tratamento: G1a (baseline), G1b (3 meses), G1c (6 meses) e pareados, em idade e gênero, com o grupo controle ( $G 2=25$ crianças sistemicamente saudáveis). Amostras de saliva estimulada foram coletadas, entre 9-11hs da manhã. Para a caracterização da população foram analisados o fluxo inicial, pH salivar, capacidade tampão e os índices ceo-d+CPO-D. Para a análise do microbioma bucal foram selecionados, aleatoriamente, 40 amostras de saliva (10G1a, 10G1b, 10G1c e 10G2) e analisadas no Human Oral Microbe Identification using Next Generation Sequencing (HOMINGS). Os testes estatísticos utilizados foram testes de One-way ANOVA, Wilcoxon, Mann-Whitney, análise do principal componente e de correspondência. Resultados: 0 $\mathrm{pH}$ inicial, fluxo salivar, capacidade tampão e os índices ceo- $d+C P O-D$ não apresentaram diferença significante entre os grupos. $\mathrm{Na}$ análise do HOMINGS, foi observado que o uso da HU (baseline, 3 e 6 meses de uso) não afetou o microbioma bucal das crianças com AF e controle pareado. Adicionalmente, não houve predominância de um microrganismo entre os grupos estudados. Conclusão: $O$ tratamento de até 6 meses com HU não afeta o perfil microbiológico bucal das crianças com AF. A ocorrência de AF não altera o microbioma salivar quando comparado com crianças sistemicamente saudáveis. FAPESP: 13469-0/2014 (Bolsa Fapesp) e 09670-7/2016 (BEPE)

TÍTULO: EFICÁCIA DO USO TÓPICO VERSUS ORAL DO ÁCIDO TRANEXÂMICO EM PACIENTES PORTADORES DE COAGULOPATIAS HEREDITÁRIAS SUBMETIDOS A EXTRAÇÕES DENTÁRIAS: UM ENSAIO CLÍNICO RANDOMIZADO.

NOME DOS AUTORES: VINICIUS RABELO TORREGROSSA*, BRUNA ALVES DOS SANTOS, ELIANA CRISTINA MIRANDA, LEANDRO DORIGAN DE MACEDO, MARIA ELVIRA PIZZIGATTI CORREA.

\section{RESUMO}

INTRODUÇÃO: O uso de agentes antifibrinolíticos por via tópica ou sistêmica é rotineiramente empregado como terapia hemostática adjuvante na prevenção e tratamento de sangramentos na cavidade bucal, e para o preparo de exodontias, em pacientes portadores de coagulopatias hereditárias (PPCH). OBJETIVO: Avaliar comparativamente a eficácia do uso tópico versus oral do Ácido Tranexâmico (ATX) em PPCH submetidos a exodontias. MÉTODOS: Este foi um estudo prospectivo Fase II, randomizado, controlado e multicêntrico, que incluiu de forma consecutiva 26 PPCH com necessidade de realizar exodontias, randomizados em dois grupos: Grupo controle - foi prescrito o uso oral do ATX (15 $\mathrm{mg} / \mathrm{Kg}$ ), $3 x$ ao dia, 7 dias, iniciando a terapêutica medicamentosa 24 horas antes da exodontia. Grupo experimental - após a exodontia foi prescrito a aplicação tópica do ATX em gel bucal bioadesivo na concentração de 8\% (Kin Exogel, Laboratorios Kin S.A., Barcelona, Espanha) sobre a 
ferida cirúrgica, e mantido com o auxílio de uma gaze estéril por 30 minutos, $3 x$ ao dia, 7 dias. $A$ terapia de reposição de fatores de coagulação foi prescrita de acordo com a doença de base e protocolos institucionais. RESULTADOS: Trinta e cinco procedimentos cirúrgicos foram randomizados, 17 no Grupo controle e 18 no Grupo experimental. Um total de 38 exodontias foram realizadas (19 em cada grupo). Apenas dois pacientes apresentaram sangramento pósoperatório associado às exodontias com necessidade de administração de dose adicional de fatores de coagulação, ambos do grupo experimental $(p=0,25)$. CONCLUSÕES: Os resultados deste estudo demonstraram a eficácia e segurança do uso tópico do ATX em gel bucal bioadesivo a $8 \%$ como medida hemostática adjuvante após exodontias em PPCH quando comparado à terapia padrão por via oral.

TíTULO: DIAGNÓSTICO DO ZIKA VÍRUS NA SALIVA. NOME DOS AUTORES: TALITA CASTRO*, MAITE SABALZA, WILLIAM ABRAMS, DANIEL MALAMUD, MARINA GALLOTTINI.

\section{RESUMO}

INTRODUÇÃO: O Zika vírus (ZIKV) é um arbovírus RNA, transmitido geralmente pelos mosquitos da espécie Aedes. Os sintomas aparecem em $20 \%$ dos infectados e incluem rash cutânea, febre, mialgia e artralgia e após a epidemia em 2016, a síndrome de Guillain-Barré em adultos e a microcefalia em recém nascidos de mulheres grávidas infectadas também foram reportados. Estudos têm postulado que a saliva é uma importante alternativa para detectar o ZIKV durante a fase aguda da doença. A amplificação Isotérmica mediada por Loop (LAMP) tem alta sensibilidade e especificidade para detectar rapidamente RNA e DNA. OBJETIVO: O objetivo deste estudo foi avaliar a eficácia da saliva e da urina em diagnosticar a infecção pelo ZIKV em indivíduos na fase aguda da doença, através da detecção do RNA pelo LAMP. MÉTODOS: 131 amostras (68 saliva e 63 urina) de 69 indivíduos apresentando sinais e sintomas para o ZIKV foram coletadas e analisadas por LAMP. Todos os indivíduos foram confirmados com ZIKV através da validação de amostras de sangue analisadas por PCR-tempo real. RESULTADOS: A média de idade dos indivíduos foi de 34,7 , sendo $46(66,7 \%)$ do sexo feminino. Os sintomas mais comuns foram rash cutânea $(56,5 \%)$, febre $(49,3 \%)$, mialgia $(49,3 \%)$ e artralgia $(39,1 \%)$. Das 68 amostras de saliva analisadas por LAMP, 45 (66,2\%) foram positivas para o ZIKV e das 63 amostras de urina, $25(39,7 \%)$ foram positivas. Quando comparada à urina, a saliva foi mais eficiente para diagnosticar o ZIKV ( $p=0.0042$; sensibilidade $=66.2 \%)$, além de apresentar maior concentração de partículas virais $(p=0.0176)$. CONCLUSÃO: A saliva é uma alternativa eficaz no diagnóstico da infecção pelo ZIKV, durante a fase aguda da doença, através do LAMP. Além disso, apresenta maior concentração de partículas virais comparada à urina.

TíTULO: ACOMPANHAMENTO DA SAÚDE BUCAL DE BEBÊS PORTADORES DA SÍNDROME DO ZIKA VÍRUS COM MICROCEFALIA NO ESTADO DO RJ.

NOME DOS AUTORES: DÉBORA TEIXEIRA MEDINA, RICART GIL MACEDO*, ANA PAULA PIRES, BRANCA HELOÍSA OLIVEIRA, LUCIANA DE FREITAS BASTOS.

\section{RESUMO}

Introdução: O Programa de Acolhimento de bebês com Microcefalia por vírus Zika da Secretaria Estadual de Saúde do RJ, realizado no Instituto Estadual do Cérebro Paulo Niemeyer (IEC), conta com a participação da odontologia para o primeiro exame bucal dos bebês e encaminhamento para acompanhamento no Núcleo de odontologia para pacientes com necessidades especiais da UERJ. Objetivo: Este estudo teve como objetivo avaliar o perfil e a saúde bucal dos bebês portadores de microcefalia acompanhados no Núcleo UERJ.

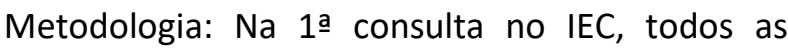
famílias são orientadas a agendar nova consulta após erupção dental para exame odontológico. Após assinatura do Termo de Consentimento, realiza-se entrevista estruturada com as mães e exame dos bebês em cadeira odontológica. Todos recebem orientação sobre cuidados bucais, assim como agendamento para consultas aos 18 e 24 meses. Os dados são inseridos no programa IBM SPSS Statistics 20.1. Resultados: Dos 30 bebês 
avaliados no 1 o semestre de 2017, com idade média de 14 meses; $49 \%$ era sexo masculino, 41\% moradores da região metropolitana do RJ, 33\% receberam aleitamento materno exclusivo até 5 meses de idade, 53\% iniciaram o consumo de açúcar antes dos 12 meses, 50\% passaram a escovar os dentes com escova e creme dental fluoretado após orientação oferecida na consulta, $57 \%$ usavam chupeta, $53 \%$ só tiveram a erupção dental iniciada entre 10 e 12 meses, e em 6\% observou-se hipoplasia de esmalte. Sobre a infecção por Zika na gravidez, $60 \%$ relataram diagnostico clinico, apenas com PCR positivo em 3 casos. Conclusão: Conclui-se que há necessidade de acompanhar a saúde bucal dos bebês com Microcefalia como uma prática de promoção da saúde.

\section{TÍTULO: COMORBIDADES DE PACIENTES VIVENDO COM HIV NA ERA PÓS-HAART.}

NOME DOS AUTORES: MARIA FERNANDA BARTHOLO*, MARINA GALLOTTINI.

\section{RESUMO}

Introdução: a terapia antirretroviral altamente ativa (HAART) transformou a doença relacionada ao HIV em uma condição crônica, pois inibe a replicação viral e diminui a depleção dos linfócitos T CD4+. Nos indivíduos em HAART, infecções oportunistas passaram a ser mais raras e alterações relacionadas ao aumento da longevidade e efeito secundário dos antirretrovirais passaram a ser observadas. Objetivo: avaliar as comorbidades de pessoas HIV positivas na era pós-HAART, que podem impactar no manejo odontológico do paciente. Método: foram examinados 101 participantes HIV positivos acima de 18 anos, por um dentista calibrado, entre agosto de 2016 a junho de 2017. Foram compilados os dados demográficos, provável meio de contaminação, nível de CD4+ e carga viral (CV) atuais e terapia em uso. Resultado: Dentre os 101, 62 eram do sexo masculino e 74 declararam-se da raça branca. A idade média foi 48 anos. Todos estavam sob HAART. Dentre 97 participantes que tinham os valores recentes de CD4, 8 exibiam $\mathrm{CD} 4<200 \mathrm{cel} / \mathrm{mm}^{3}, 18$ entre 200 e $499 \mathrm{cel} / \mathrm{mm}^{3}$ e 71 exibiam CD4?500cel/ $\mathrm{mm}^{3}$. Apenas 3 participantes exibiam CV acima dos limites de detecção. Dos 101 participantes, 85 reportaram pelo menos uma comorbidade. Pacientes com 20 anos ou mais de diagnóstico da infecção pelo HIV apresentaram maior prevalência de hipertensão arterial, diabetes mellitus, hepatites virais e lipodistrofia $(p<0,05)$. Conclusão: comorbidades relacionadas a imunodepressão foram pouco prevalentes. No momento do exame a comorbidade mais prevalente foi a lipodistrofia $(49,5 \%)$, seguida pelas desordens psiquiátricas $(37,6 \%)$, ambas mais prevalentes entre as mulheres. Neutropenia e Sarcoma de Kaposi apresentaram significância estatística em relação ao $C D 4<200(p<0,05)$.

TítULO: AVALIAÇÃO DAS ALTERAÇÕES DE PALADAR EM PACIENTES SUBMETIDOS A TRANSPLANTE DE CÉLULAS HEMATOPOIÉTICAS.

NOME DOS AUTORES: MARIANA HENRIQUES FERREIRA*, LETICIA BEZINELLI, FERNANDA DE PAULA EDUARDO, NELSON HAMERSCHLAK, LUCIANA CORRÊA.

\section{RESUMO}

Introdução: Pacientes submetidos ao transplante de células hematopoiéticas (TCH) podem desenvolver diversos efeitos colaterais, um deles é a disgeusia. Objetivo: Detectar a frequência da disgeusia, verificar quais sabores ficam mais alterados e avaliar o impacto dessas alterações na qualidade de vida do paciente. Metodologia: Trinta pacientes adultos provaram soluções aquosas contendo concentrações fracas e fortes de ácido cítrico (azeda), sal (salgada), açúcar (doce), café (amarga) nos períodos pré-condicionamento -TO, neutropenia -T1 e pega da medula -T2. Foi também observada em cada período a ausência ou presença de despapilação lingual e o impacto da disgeusia na qualidade de vida. Resultados: A principal alteração foi a diminuição da sensação dos sabores, principalmente do amargo forte (42.9\%) e do doce forte (27.3\%). Houve falha na detecção do tipo de sabor, sendo mais frequentes os sabores doce $(24.7 \%)$ e salgado (22.1\%). As alterações foram mais frequentes nos períodos $\mathrm{T} 1$ e T2, com diferenças significativas em relação a T0 
para falha da sensação do sabor doce fraco $(p=0.041)$, do amargo forte $(p=0.007)$ e do salgado forte $(p<0.001)$. A despapilação lingual foi significativamente maior nos períodos T1 e T2 em relação ao T0 $(p<0.001)$. Na avaliação da qualidade de vida, $31.2 \%$ dos pacientes apontaram dificuldade moderada a intensa de sentir o sabor dos alimentos. Portanto, a disgeusia é uma alteração comum nos pacientes submetidos ao $\mathrm{TCH}$ e é derivada principalmente de alterações na sensação da intensidade dos sabores. Conclusão: A despapilação lingual pode estar associada à disgeusia e esses dois fatores foram mais frequentes durante a neutropenia e persistiram após a pega da medula. Essas alterações impactaram na qualidade de vida dos pacientes durante o $\mathrm{TCH}$.

TítULO: AVALIAÇÃO DA DEMANDA E DO ATENDIMENTO ODONTOLÓGICO PÚBLICO AOS PACIENTES COM NECESSIDADES ESPECIAIS NO ESTADO DO RJ.

NOME DOS AUTORES: RICART GIL MACEDO*, GUSTAVO SINES, BRUNA STRONG, ALINE QUINTELA, DEBORA TEIXEIRA MEDINA.

\section{RESUMO}

Introdução: É dever do Estado prestar atendimento odontológico de média e alta complexidade e neste contexto se insere a atenção ao paciente com necessidades especiais. No Rio de Janeiro o serviço é oferecido no Hospital Estadual Carlos Chagas e no Núcleo de atendimento odontológico PPC UERJ. Todos os municípios solicitam vaga através do Sistema Estadual de Regulação (SER). Objetivo: Este estudo tem como objetivo avaliar a demanda para o serviço público de odontologia para pacientes com necessidades especiais do Estado do RJ, o acesso através do SER e a realização do atendimento. Métodos: Foram levantadas as informações de solicitações de consultas para o serviço no SER entre os meses de janeiro a setembro de 2017, assim como avaliados os prontuários dos pacientes atendidos. Resultados: Foram realizadas 360 solicitações de consultas por 11 municípios no SER. O Transtorno do Espectro Autista foi a deficiência mais citada
(19\%). Em relação a necessidade de tratamento, a raspagem-alisamento foi a de maior frequência $(76,8 \%)$, seguida de restauração $(59,2 \%)$ e exodontia (53,9\%). O comparecimento à consulta pelos agendados foi de $83,6 \%$, sendo que destes, 252 casos foram tratados no ambulatório, 84 submetidos ao protocolo de sedação consciente e apenas 38 submetidos a anestesia geral no centro cirúrgicos. Conclusão: Conclui-se que a demanda para o atendimento odontológico público aos pacientes com necessidades especiais no Estado do RJ mostra-se elevada, sendo efetivo o agendamento via sistema de regulação, assim como $o$ atendimento prestado.

TÍTULO: IMPACTO DAS CONDIÇÕES BUCAIS PRÉ E PÓS-TRANSPLANTE HEPÁTICO NA QUALIDADE DE VIDA DE CRIANÇAS: ESTUDO LONGITUDINAL.

NOME DOS AUTORES: EVELYN ALVAREZ VIDIGAL*, JENNY ABANTO, FÁBIO ABREU ALVES, MARCELO BÖNECKER.

\section{RESUMO}

Alterações bucais pré e pós-transplante hepático em crianças podem causar impacto na qualidade de vida relacionada à saúde bucal (QVRSB). Os objetivos do estudo foram avaliar o impacto das condições bucais pré-transplante na QVRSB de crianças; avaliar $\mathrm{O}$ impacto do tratamento odontológico na QVRSB antes do transplante e avaliar o impacto das condições bucais na QVRSB após 5 meses do transplante. Foram avaliadas 60 crianças menores de 5 anos com doença hepática no AC Camargo Câncer Center. Antes do transplante, foram avaliadas a presença de cárie dentária, defeitos de esmalte, pigmentações dentárias, doença periodontal e lesões em mucosa oral. O responsável respondeu o questionário de QVRSB: B-ECOHIS. Os tratamentos odontológicos foram realizados e após 7 dias o B-ECOHIS foi aplicado. Após o transplante, as crianças foram acompanhadas e o B-ECOHIS foi aplicado em períodos de 1, 3 e 5 meses. 0 modelo de regressão ajustado demonstrou que crianças com 2 a 4 anos de idade ( $R T=2.17 ; p=0.04)$, com lesões de cárie não tratada $(R T=1.35 ; p<0.05)$ e pigmentações dentárias ( $R T=1.85 ; \mathrm{p}<0.05)$ apresentaram impacto 
negativo na QVRSB. As médias dos escores do BECOHIS pré e pós-tratamento odontológico diminuíram $(p<0.05)$ indicando melhora na QVRSB. Após 5 meses do transplante, a presença de lábios ressecados ( $R T=55.54 ; p<0.05)$, queilite angular ( $R T=86.91 ; p<0.05)$ e candidíase oral $(R T=122.57$; $p<0.05)$ foram associados a uma pior QVRSB. Conclui-se que a presença de pigmentações dentárias e lesões de cárie não tratada em crianças menores de 5 anos tiveram impacto negativo na QVRSB antes do transplante. O tratamento odontológico antes do transplante melhora a QVRSB. A presença de lábios ressecados, queilite angular e candidíase após 5 meses do transplante afetam negativamente a QVRSB. Patrocinador: $\mathrm{CNpQ}$ - Conselho Nacional de Apoio de Pesquisa

TíTULO: AVALIAÇÃO PERIODONTAL DE PACIENTES CIRRÓTICOS CANDIDATOS AO TRANSPLANTE HEPÁTICO.

NOME DOS AUTORES: BRUNA DI PROFIO, KAREN LOPÉZ ORTEGA, MARINELLA HOLZHAUSEN, CLÁUDIO MENDES PANNUTI.

\section{RESUMO}

Pacientes cirróticos apresentam comprometimento da defesa imunológica sistêmica, o que pode aumentar o risco de infecções, como as doenças periodontais. 0 objetivo dessa investigação foi comparar pacientes cirróticos candidatos ao transplante com controles sem hepatopatia, em relação à prevalência, extensão e severidade de doença periodontal. Foram submetidos a exame periodontal completo 50 pacientes cirrótico (grupo cirrose) e 50 sujeitos sem hepatopatia (grupo controle). Os grupos foram pareados segundo sexo, idade e tabagismo. Foi aplicado questionário estruturado para registro de dados demográficos, condição hepática, saúde sistêmica e história médica relacionada a desordem hepática. Foi realizado exame periodontal completo de seis sítios por dente em boca toda: recessão gengival (RG), profundidade clínica de sondagem (PCS), sangramento a sondagem (SS) e índice de placa visível (IPV). Perda clínica de inserção (PCI) foi calculada pela soma da RG e PCS mensuradas em cada sítio. Pacientes com cirrose apresentaram maior prevalência de periodontite do que os controles sadios $(p<0.001)$. Além disso, apresentaram maior prevalência média de sítios com $\mathrm{PCl}$ de $3 \mathrm{~mm}(p=0,005)$ ou mais e $5 \mathrm{~mm}$ ou mais $(p=0.004)$, maior número médio de sítios com $\mathrm{PCl}$ de $5 \mathrm{~mm}$ ou mais $(p=0,009)$, maior média de RG ( $p<0.001)$ e maior número de dentes ausentes que 0 grupo controle $(p=0,02)$. CONCLUSÃO: Pacientes cirróticos apresentaram maior prevalência, extensão e severidade de periodontite do que controles sem hepatopatia.

TíTULO: EFEITOS DO ESTRESSE NO PADRÃO DE SECREÇÃO SALIVAR DA GLÂNDULA PARÓTIDA: ESTUDO PILOTO.

NOME DOS AUTORES: CAMILLA VIEIRA ESTEVES*, SILVIA VANESSA LOURENÇO, WALTER L SIQUEIRA, Y. XIAO, CELSO AUGUSTO LEMOS.

\section{RESUMO}

Introdução: A análise do proteoma das glândulas salivares em especial da glândula parótida, são importantes para a compreensão das proteínas individuais presentes na saliva humana e do seu comportamento na saúde, para desta forma entender a patogênese de certas doenças. Objetivo: Nossa hipótese é de que o estresse interfira na liberação de proteínas da glândula parótida. Métodos: Foram selecionados dois indivíduos do sexo feminino, normotensos, com idade semelhantes $(28$ e 30 anos respectivamente), que foram instruídos a coletar saliva da glândula parótida por um período de 10 minutos sob fluxo contínuo $(1 \mathrm{~mL} / \mathrm{min})$ para não haver influência direta entre a quantidade de saliva coletada e a de proteínas em duas ocasiões: antes e após a apresentação de trabalho científico. As proteínas provenientes da saliva da parótida estimulada $(20 \mu \mathrm{g})$ foram submetidas a espectrometria de massa e eletroforese em gel de poliacrilamida contendo dodecil sulfato de sódio (SDS-PAGE) e os dados obtidos foram confrontados com banco de dados humanos. Resultados: De acordo com a análise estática de Mann-Whitney demonstraram o mesmo padrão de secreção proteica $(p=0,016)$ sob estresse e no estado de não estresse $(p<.01)$. Porém, houve aumento no total 
de proteínas secretadas, sendo 312 proteínas no momento de não estresse e 509 no momento de estresse, sendo Alpha-amylase 1, Zinc-alpha-2glycoprotein, Immunoglobulin heavy constant alpha 1, Prolactin-inducible protein, Cystatin-AS, Myosin-reactive immunoglobulin kappa chain variable regionencontradas apenas no momento estresse. Conclusão: Este estudo piloto concluiu que existem diferenças na composição proteômica da saliva da parótida e que a situação de estresse induz a 